\title{
Treatment of kitchen wastewater using Eichhornia crassipes
}

\author{
Rijwana Parwin ${ }^{1}$, and Kakoli Karar Paul ${ }^{2, *}$ \\ ${ }^{1}$ Research Scholar, Department of Civil Engineering, NIT, Rourkela, 769008, India \\ ${ }^{2}$ Assistant Professor, Department of Civil Engineering, NIT, Rourkela, 769008, India
}

\begin{abstract}
The efficiency of Eichhornia crassipes for treatment of raw kitchen wastewater was studied in the present research work. An artificial wetland of 30 liter capacity was created for phytoremediation of kitchen wastewater using Eichhornia crassipes. Kitchen wastewater samples were collected from hostel of an educational institute in India. Samples were characterized based on physical and chemical parameters such as $\mathrm{pH}$, turbidity, total hardness, nitrate-nitrogen, ammonium-nitrogen, sulphate, dissolved oxygen, total organic carbon and total dissolved solid. The physico-chemical parameter of kitchen wastewater samples were analysed for durations of 0 (initial day), 4 and 8 days. After 8 days of retention period, it was observed that $\mathrm{pH}$ value increases from 6.25 to 6.63 . However, percentage reduction for turbidity, total hardness, nitratenitrogen, ammonium-nitrogen, sulphate, dissolved oxygen, total organic carbon and total dissolved solid were found to be $74.71 \%, 50 \%, 78.75 \%$, $60.28 \%, 25.31 \%, 33.33 \%, 15.38 \%$ and $69.97 \%$, respectively. Hence water hyacinth (Eichhornia crassipes) is found efficient and easy to handle and it can be used for low cost phytoremediation technique.
\end{abstract}

\section{Introduction}

Wastewater generated from domestic and industrial activities may be a vital resource if it can be reuse for safe utilization in agriculture [1]. Domestic wastewater contains both black and grey wastewater. Greywater constituted $80 \%$ of the total wastewater with maximum contribution (44\%) from the kitchen [2]. In developing countries, wastewater from kitchen outlet with high organic material and oil and grease were disposed into rivers and stream without treatment. The characteristics of kitchen wastewater are quite variable among households due to the type of cooking and dietary preference [3]. The presence of less number of pathogenic microorganism and toxic elements in the kitchen wastewater reduces health risk and treatment cost in comparison to other wastewater. The nutrient content of kitchen wastewater can be utilized for reuse in agricultural sector if it can be treated using an ecofriendly, sustainable and low cost technique like phytoremediation. In recent years, the artificial constructed wetland with floating aquatic plant species such as water hyacinth

\footnotetext{
* Corresponding author: kkpaul@nitrkl.ac.in
} 
[4], water lettuce [5], duck weed [6], vetiver grass [7] have been used for treatment of wastewater. Eichhornia crassipes has been considered as problematic aquatic free floating weed because of its uncontrolled growth in water bodies and it is difficult to control and eradicate this plant from water bodies. However, its ability to uptake heavy metals from aquatic ecosystem has been considered as a bioindicator [8].

Limited research has been done on the phytoremediation technique for treatment of kitchen wastewater using Eichhornia crassipes [9]. The aim of the present study is to assess the efficiency of water hyacinth (Eichhornia crassipes) for the treatment of kitchen wastewater for different retention periods.

\section{Materials and methods}

\subsection{Experimental set up}

A bench-scale shallow pond containing water hyacinth was constructed in the premise of the CVR Hall of Residence, NIT Rourkela, India $\left(22.2525^{\circ} \mathrm{N}, 84.9046^{\circ} \mathrm{E}\right)$. Wastewater samples were collected from kitchen outlet. The study set up consists of wetland unit $(30 \mathrm{~L})$ with water hyacinth (phytoremediation) and another wetland unit $(30 \mathrm{~L})$ without water hyacinth to serve as a control and for identifying the pattern of pollution reduction. Healthy young water hyacinth plants collected from nearby pond were chosen for efficient removal of contaminants from kitchen wastewater. The roots of the water hyacinth plants were washed carefully with tap water to remove adhering dirt. Then these plants were kept few weeks in tap water for acclimatization in the stock container. Initially experimental set up was properly cleaned with tap water. The physico-chemical parameters of kitchen wastewater sample were tested at durations of 0 (initial day), 4 and 8 days. Removal efficiency (RF) was calculated using eq. (1). Where $C_{i}$ and $C_{e}$ are the influent and effluent concentration respectively.

$$
R F=\frac{C_{i}-C_{e}}{C_{i}} \times 100
$$

\subsection{Experimental procedure for analysis}

The measurement of $\mathrm{pH}$, and temperature were done in the sampling site. Then, collected wastewater samples were taken to laboratory for further detailed analysis of physicochemical parameters such as turbidity, total hardness (TH), total dissolved solid (TDS), sulphate, dissolved oxygen (DO), nitrate-nitrogen, ammonium-nitrogen and total organic carbon (TOC). The analysis procedures are summarized in Table 1. 
Table 1. Experimental procedure for characterization of kitchen wastewater.

\begin{tabular}{|c|c|c|}
\hline Physico-chemical parameters & Standards adopted & Methods / Instrument used \\
\hline Colour & - & Eye observation \\
\hline Odour & - & Olfactory sense \\
\hline pH & - & HQ40D (HACH) \\
\hline Turbidity (NTU) & - & 2100 Q $(\mathrm{HACH})$ \\
\hline Total hardness (ppm) & IS:3025(Part21):2009 & EDTA method \\
\hline DO (ppm) & IS:3025(Part38):2003 & Winkler method \\
\hline TS, TDS, TSS (ppm) & $\begin{array}{c}\text { IS:3025(Part15, } \\
16,17): 2009\end{array}$ & Gravimetric Method \\
\hline Sulphate (ppm) & IS:3025(Part24):2003 & Turbidity Method \\
\hline Nitrate-Nitrogen (ppm) & - & DR/890:8039 (HACH) \\
\hline Ammonium-Nitrogen (ppm) & - & $\begin{array}{c}\text { IntelliCAL ammonium } \\
\text { ISENH4181 HACH }\end{array}$ \\
\hline Total organic carbon (ppm) & - & HACH DR/890:10129 \\
\hline
\end{tabular}

\section{Results and discussion}

After 8 days of experiment with 4 days interval, physico-chemical parameters were evaluated to check the effectiveness of Eichhornia crassipes for kitchen wastewater treatment. As shown in Fig.1, a small increase was observed in $\mathrm{pH}$ range from 6.25 to 6.63 $(6.08 \%)$ by phytoremediation whereas $17.44 \%$ decrease of $\mathrm{pH}$ range was observed in control. Study by [10] found an increase of $13 \% \mathrm{pH}$ value while treating the domestic wastewater using Eichhornia crassipes. Study by [11] observed that aeration reduces rate of $\mathrm{pH}$ reduction was higher in phytoremediation treatment with Eichhornia crassipes in comparison to treatment by Pistia stratiotes.
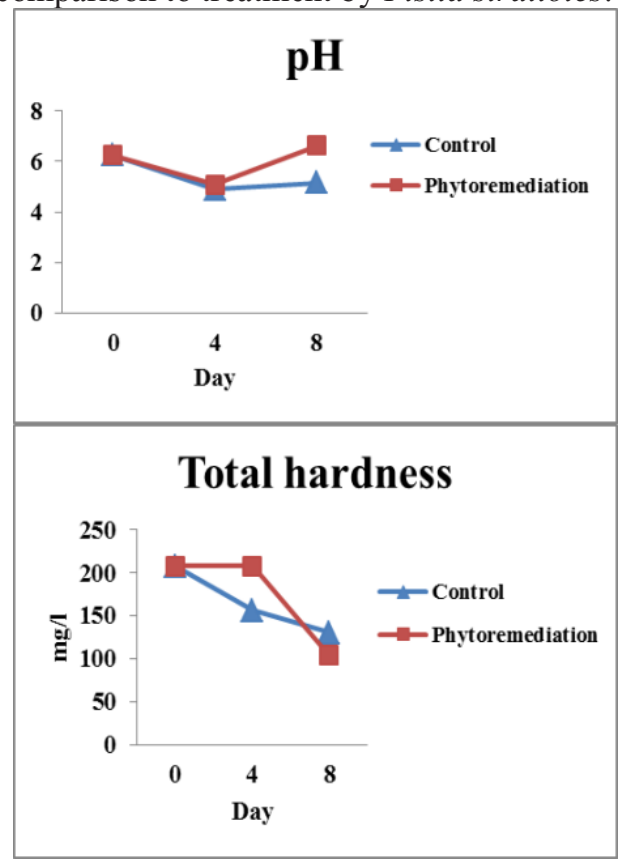

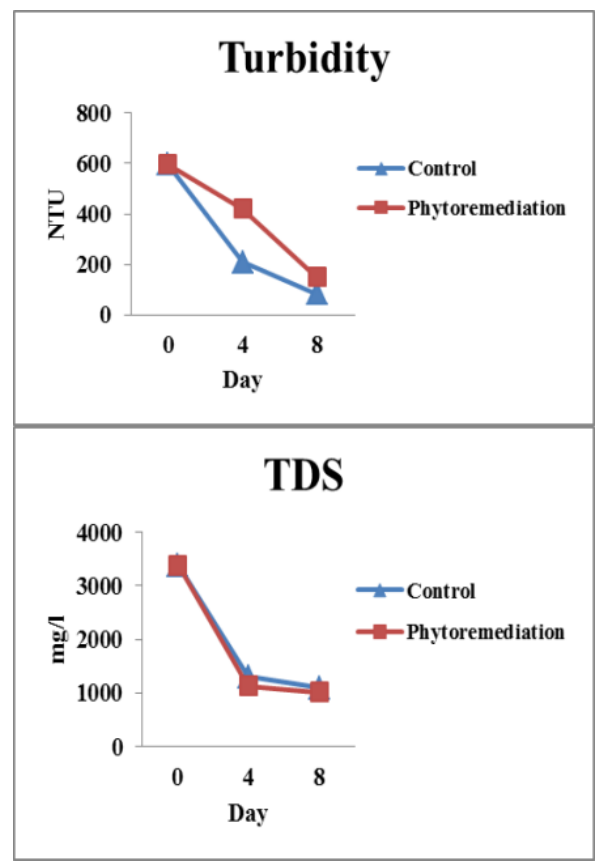

Fig. 1. The removal of $\mathrm{pH}$, turbidity, total hardness and total dissolved solid (TDS) during different time interval. 
As demonstrated in Fig. 1 turbidity showed significant reduction from 596.4 NTU to $83.58 \mathrm{NTU}(85.98 \%)$ in control whereas $74.71 \%$ reduction efficiency occurred by phytoremediation. The reduction of total hardness was $37.5 \%$ for control whereas $50 \%$ reduction for phytoremediation. Eichhornia crassipes showed good results over control for total hardness reduction. In this study, the removal efficiency for total dissolved solid was $67.72 \%$ in control whereas $69.97 \%$ for phytoremediation. About $11 \%$ reduction efficiency for TDS was observed by [10] while treating the domestic wastewater using Eichhornia crassipes. However, reduction of $26 \%$ for TDS was reported by [12] in Eichhornia crassipes.

In this study, $\mathrm{NH}_{4}{ }^{+}-\mathrm{N}$ was found to be removed (60.28\%) by phytoremediation (Fig. 2) when compared to the control $(48.22 \%)$. Study by [10] reported $95 \%$ reduction efficiency for $\mathrm{NH}_{4}{ }^{+}-\mathrm{N}$ while treating the domestic wastewater using Eichhornia crassipes. However in this study, $\mathrm{NO}_{3}^{-}-\mathrm{N}$ reduction was $78.75 \%$ and $65.62 \%$ by phytoremediation and control, respectively (Fig. 2). It was observed that sulphate reduction in control was $69.13 \%$ whereas only $25.31 \%$ by phytoremediation. Reduction efficiency for TOC was found $13.67 \%$ and $15.38 \%$ for control and phytoremediation, respectively.
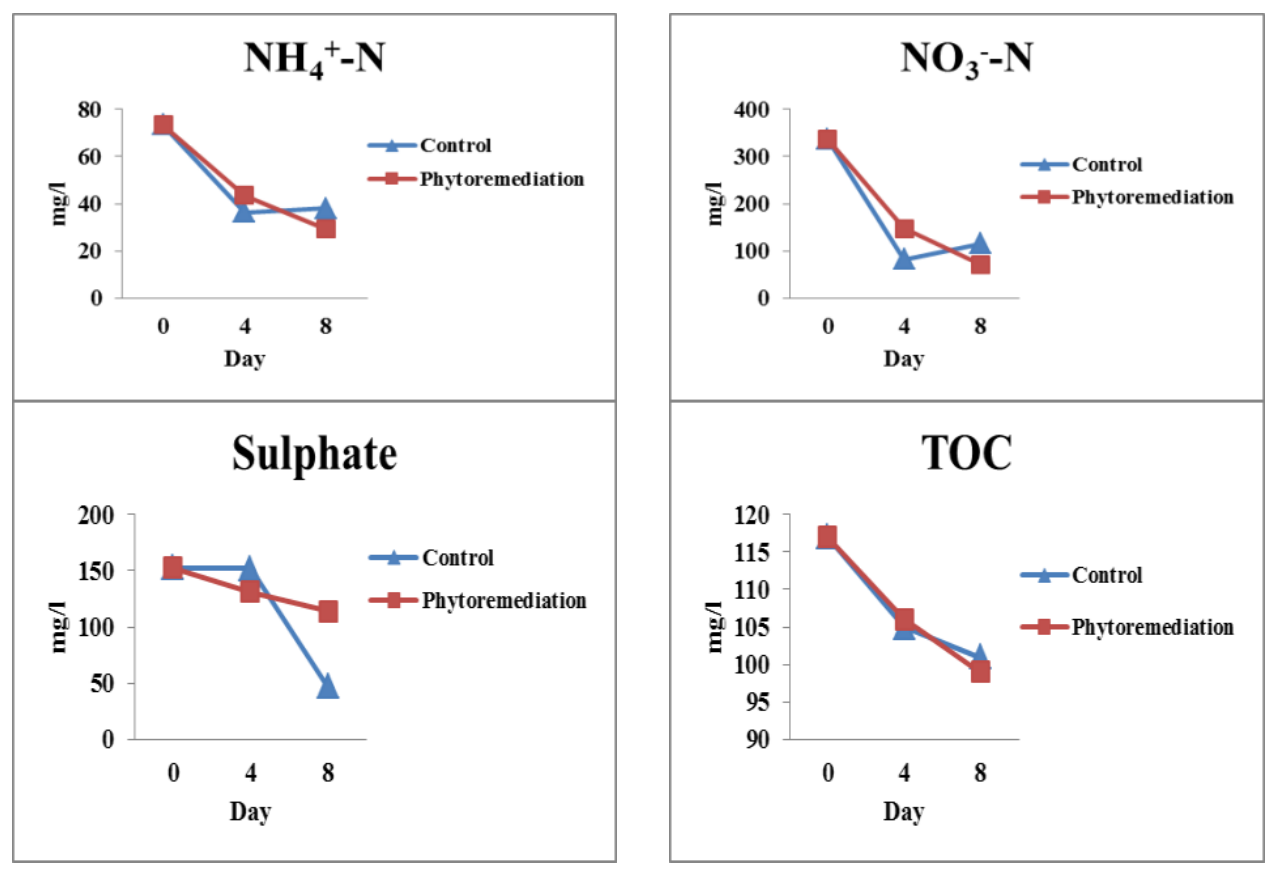

Fig. 2. The removal of ammonium-nitrogen, nitrate-nitrogen, sulphate and total organic carbon (TOC) during different time interval.

In this study, reduction efficiency for DO was same $(33.33 \%)$ in both control and phytoremediation due to microbial and decomposition activities associated with floating plants (Fig. 3). Aerobic micro-organisms need oxygen for degradation of organic content present in raw kitchen wastewater thus reducing oxygen level in sample on 4th day but on 8th day again oxygen level increases. Dense plant cover on water surface reduces atmospheric oxygen diffusion. The floating plants play vital role in tranferring atmospheric oxygen $(30 \%-40 \%)$ to rhizospere through aerenchyma (internal gas space) for aerobic microbial activity [4]. 


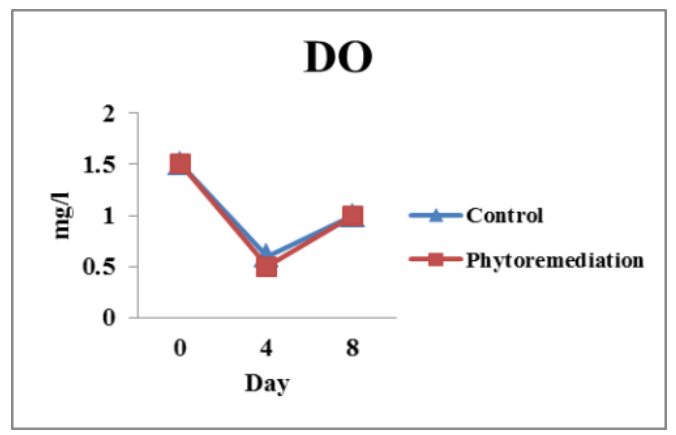

Fig. 3. The removal of dissolved oxygen (DO) during different time interval.

\section{Conclusions}

In recent years more emphasis has been focused on low cost, eco-friendly, sustainable and green technique like phytoremediation. In present study, an attempt has been made to study on effectiveness of floating aquatic plant, water hyacinth (Eichhornia crassipes) for the treatment of kitchen wastewater during different retention periods. After 8 days of retention period, phytoremediation showed good reduction efficiency in total hardness $(50 \%)$, nitrate-nitrogen $(78.75 \%)$, total organic carbon $(15.38 \%)$, ammonium-nitrogen $(60.28 \%)$ and total dissolved solid (69.97\%) whereas, reduction efficiency of turbidity (74.71\%) and sulphate $(25.31 \%)$ were found less in comparison to control condition. However, phytoremediation showed an increase of $\mathrm{pH}(6.08 \%)$. Hence, water hyacinth (Eichhornia crassipes) is found efficient in treatment of kitchen wastewater. It can be used for low cost phytoremediation technique.

\section{References}

1. M. Raychaudhuri, S. Raychaudhuri, S.K. Jena, A. Kumar, R.C. Srivastava, DWM Bulletin No. 71, Directorate of Water Management, Bhubaneswar, India, 43 (2014).

2. K. A. Vakil, M.K. Sharma, A. Bhatia, A.A. Kazmi, S. Sarkar, Separa. and Purifi. Tech. 130, 160-166. (2014).

3. R.M.S.R. Mohamed, C.M. Chan, H.B. Ghani, M. A. M. Yasin, A.H.M. Kassim, Int. J. of Zero Waste Genera. 1, 1 (2013).

4. A. Valipour, V.K. Raman, Y.H. Ahn, Water, 7, 329-347 (2015).

5. Q. Lu, Z.L. He, D.A. Graetz, P.J. Stoffella, X. Yang, Environ. Sci. Pollut. Res. 17, 8496 (2010).

6. A. Priya, K. Avishek, G. Pathak, Environ. Monit. Assess. 184, 4301-4307 (2012).

7. N. Girija, S.S. Pillai, M. Koshy, Ecoscan 1, 267-273 (2011).

8. E.S. Priya, P.S. Selvan, Arab. J. of Chem. 10, S3548-S3558 (2017).

9. O.O. Seun, O. N. Adeshina, K. Kolawole, T.S. Adedeji, A. Jamal, Int. J. of Sci. and Engi. Res. 6, 1, 834 (2015).

10. S. Rezania, M.F.M. Din, S.M. Taib, F.A. Dahalan, A.R. Songip, L. Singh, H. Kamyab, Int. J. of Phytorem. 18, 7, 679-685 (2016).

11. C.O. Akinbile, M.S. Yusoff, Int. J. of Phytorem. 14, 3, 201-211 (2012).

12. P. Moyo, L. Chapungu, B. Mudzengi, Adv. Appl. Sci. Res. 4, 4, 55-62 (2013). 